\title{
Elaboração de vídeo-aula para ensino superior
}

\author{
Roberta de Souza Leone ${ }^{a}$, Cristina Mesquita ${ }^{b}$, Rui Pedro Lopes ${ }^{c}$ \\ ${ }^{a}$ Universidade Tecnológica Federal do Paraná, Departamento Acadêmico de Alimentos e Engenharia \\ Química, Campo Mourão, Brazil, robertaleone@utfpr.edu.br, ${ }^{\mathrm{b}}$ Instituto Politécnico de Bragança, \\ Centro de Pesquisa em Educação Básica, Bragança, Portugal, cmmgp@ipb.pt ${ }^{\mathrm{c} I n s t i t u t o ~ P o l i t e ́ c n i c o ~ d e ~}$ \\ Bragança, Centro de Digitalização e Robótica Inteligente, Bragança, Portugal, rlopes@ipb.pt.
}

\begin{abstract}
Resumo
Historicamente, o processo de ensino-aprendizagem assume o centro da atividade na atuação do professor e se baseia na transferência de conhecimento do professor para o aluno. Hoje, os professores têm como público-alvo uma geração de alunos com acesso rápido e dinâmico a vídeos disponíveis nas plataformas digitais. Muitos estudantes universitários recorrem a esse tipo de vídeo para aprender sobre qualquer assunto, inclusive aquele que foi tratado em sala de aula. Se essa prática já é comum na rotina dos estudantes, em situações de emergência ou de necessidade de distanciamento social, pode mesmo vir a ser essencial, como principal apoio ao processo educacional. Embora o vídeo seja umas das tecnologias que se destacam como objeto de aprendizagem, capacitar o professor para o desenvolvimento e a utilização da vídeo-aula como uma possibilidade de enriquecimento do ensino, passa a ser crucial. Assim, este trabalho propõe apresentar uma forma de elaboração de vídeo-aulas para ensino super considerando o uso de dois programas de gravação de vídeo e dois programas de edição de vídeo. A experiência demonstrou que o programa de gravação e edição Active Presenter é um programa de fácil entendimento e manipulação, enquanto que os programas de gravação OBS Studio e de edição Shotcut possuem mais funções, mas são menos intuitivos, exigindo maior tempo e comprometimento do professor para aprender a utilizá-los. A melhor experiência foi a gravação no Active Presenter e a edição no Shotcut, pois permitiu a retirada das partes desnecessárias do vídeo, produzindo uma vídeo-aula com ajuste fino na edição.
\end{abstract}

Palavras-chave: Edição de vídeo-aula, Gravação de vídeo-aula. 


\section{Introdução}

Os materiais didáticos, dentre eles as vídeo-aulas, são indispensáveis para comunicação de conteúdo na educação remota. Sua produção envolve processos que seguem um fluxo bem definido e devido a sua importância, sua elaboração deve priorizar a qualidade do material (Spanhol \& Spanhol, 2009).

Em diversos locais de ensino à distância (EAD), as vídeo-aulas são aulas gravadas em estúdio devidamente preparado com cenografia e iluminação específica. Os professores, nestes estúdios, dispõem de recursos técnicos como: câmera, captura de tela do computador, microfone unidirecional com cancelador de eco, câmera robô e teleprompter. Além do professor, estão envolvidos a equipe técnica, que fica responsável pelo enquadramento do plano visual, linguagem, tempo de gravação, apresentação visual do professor, som, luz e acompanhamento do roteiro pré-produzido. Após a gravação a equipe técnica edita o vídeo e a equipe pedagógica valida a vídeo-aula para que possa ser disponibilizada para os alunos. Este processo demora, em média, de 8 a 12 horas para cada aula de 50 minutos produzida (Spanhol \& Spanhol, 2009).

No contexto atual, muitos programas gratuitos de gravação e edição de vídeos estão disponíveis para serem utilizados em computadores pessoais, sem a necessidade de placa de vídeo, câmera ou microfone profissionais. Os tutoriais, em vídeo ou em forma de manuais, que ensinam a utilizar estes programas, são facilmente encontrados. Com o aumento da velocidade da internet e redução do custo de tecnologia multimídia, vídeos têm sido amplamente utilizados no sistema educacional, seja ele presencial ou não. A popularização de plataforma gratuita de compartilhamento de vídeos, como o YouTube, contribuiu para isso, já que ele é o segundo site com maior engajamento global, perdendo apenas para o Google (Alexa, [s.d.]).

Além de utilizar conteúdo em vídeo disponíveis na internet, o professor que desejar pode produzir de forma efetiva suas próprias vídeo-aulas. A vantagem desse tipo de plataforma de conteúdo é que os alunos podem aprender no seu ritmo, rever partes do vídeo de seu interesse e isso pode melhorar o engajamento e deixar a aprendizagem mais eficaz (Chen, 2013).

A produção de vídeos educacionais exige conhecimentos técnicos, capacitação adequada, custos e disponibilidade de tempo do professor para apropriar-se dessa ferramenta (BoniniRocha et al., 2014). Desta forma, este artigo tem por objetivo apresentar o fluxo de processos de produção de uma vídeo-aula pelo próprio professor, avaliando as características de dois programas de gravação e dois programas de edição. 


\section{Material e Métodos}

Este é um estudo de caso da experimentação de uma professora no uso de ferramentas de gravação e edição de vídeo-aulas. A gravação da vídeo-aula obedeceu as etapas do fluxograma da Figura 1.

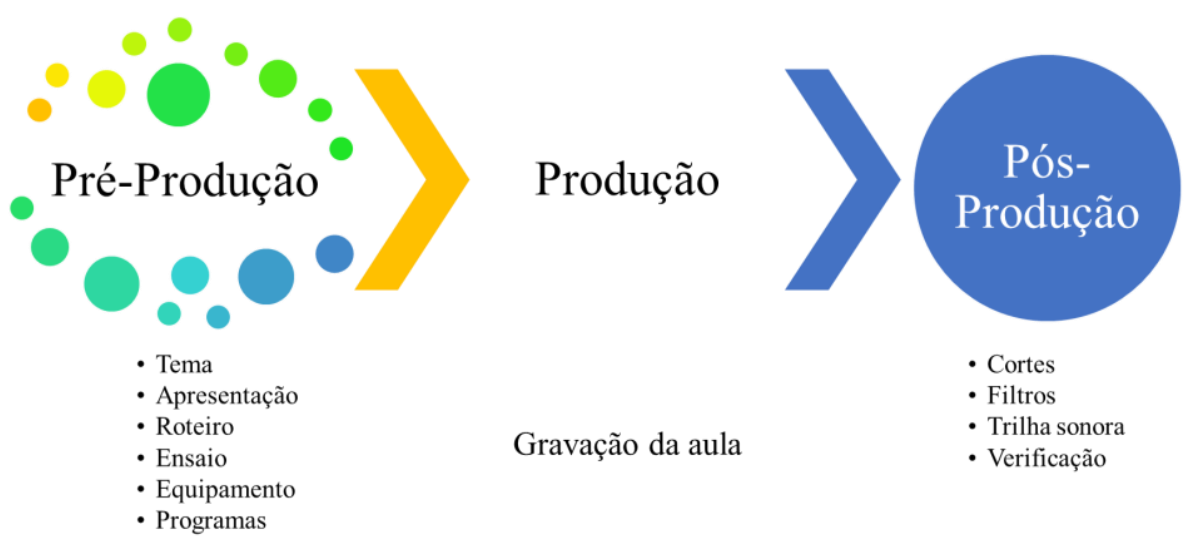

Fig. 1 Etapas da produção de vídeo-aula

Fonte:o autor

\subsection{Pré-Produção}

A etapa de pré-produção da vídeo-aula inclui a escolha do tema da aula, a forma de apresentação deste tema, a preparação do material e a elaboração do roteiro. Neste experimento optou-se por apresentar o conteúdo através de uma apresentação do PowerPoint e um vídeo. Foi feito um ensaio e adequações no roteiro foram feitas para se adequar à apresentação. Os programas de gravação e edição de vídeos foram selecionados e instalados em suas versões gratuitas, com excessão do PowerPoint, cuja licença de uso foi adquirida. Os teste foram executados em um computador portátil, com hardware composto de procesador Intel Core i5-3337U 1,8 GHz, memória RAM de 4,0 GB e sistema operacional Windows 10 Home Single Language de 64 bits. A voz de narração do vídeo foi gravada com o auxílio de um fone de ouvido convencional com microfone acoplado.

\subsection{Produção}

A etapa de produção é o momento da gravação. A vídeo-aula foi gravada nos programas OBS Studio e Active Presenter. Ela foi elaborada de forma que o aluno veja a apresentação 
de slides juntamente com a imagem da professora explicando o conteúdo da aula. A imagem da professora foi captada pela webcam própria do computador (720p 16:9 30fps).

\subsection{Pós-Produção}

A pós-produção inclui a edição e finalização do vídeo, quando os ajustes necessários são feitos. Foram utilizados os programas Active Presenter e Shotcut. As partes com erros foram cortadas. Um filtro de ruído foi aplicado para reduzir o chiado produzido durante a gravação da voz. Cada programa de edição possui ferramentas de filtros de áudio e vídeo. No Shotcut o filtro de ruído é denominado Normalizar: uma passagem"; no Active Presenter é denominado Aplicar redução de áudio profissional". Uma música livre de direitos autorais foi colocada como som de fundo. Uma vinheta e uma tela final com os créditos de produção foram acrescentadas. A vídeo-aula foi verificada, exportada para formato mp4 e hospedada no YouTube para posterior divulgação.

\section{Resultados e discussões}

Em momentos que a situação nos coloca longe da sala de aula, por medidas de distanciamento social ou por impossibilidade do estudante estar na sala de aula no horário estabelecido para tal, os professores podem utilizar ferramentas que garantam que o conhecimento vai chegar até o aluno.

Os recursos pedagógicos mais utilizados pelo professor do ensino superior, em sala de aula presencial, são o quadro negro (ou lousa branca) e a apresentação multimídia. Estes recursos podem ser reproduzidos pelo próprio professor em uma vídeo-aula, utilizando-se de um computador, acesso à internet, microfone externo (fone de ouvido do celular) ou interno (do próprio computador), webcam do computador ou do celular. Desta forma, não se faz necessário uma estrutura física com equipamentos de gravação profissional.

Não é possível deixar o tempo do professor fora da lista de ferramentas, pois a preparação de uma vídeo-aula demanda mais tempo do que a preparação de uma aula presencial, já que a produção do vídeo inicia a partir do material que seria utilizado na aula presencial. Além de que o professor vai precisar de tempo e disposição para aprender a manipular os programas de gravação e edição de vídeos e as plataformas de divulgação dos mesmos. 


\subsection{Pré-Produção}

O tema escolhido foi - Đperações preliminares no processamento de frutas e hortaliças". A apresentação foi estruturada pensando em contar uma história, que se inicia com o questionamento: Por que processar os alimentos?, passando pelas etapas de transporte dos vegetais, limpeza, seleção e descascamento. Foram utilizadas figuras livres de direitos autorais (Flaticon, [s.d.]) e animações para tornar a apresentação mais dinâmica e criar um ponto focal no vídeo para onde o aluno deve direcionar sua atenção. Um roteiro de falas foi elaborado para que a professora não esquecesse de nada que era importante. Durante o ensaio, com a falas e a apresentação, o roteiro foi alterado para que a explicação tivesse o mesmo tempo das animações.

Os programas de gravação de tela OBS Studio e Active Presenter, e os programas de edição de vídeo Active Presenter e Shotcut, foram selecionados após uma breve pesquisa sobre programas de livre acesso. Existem muitos tutoriais de como utilizar cada um dos programas, na forma de vídeos ou manuais, facilmente encontrados na web, que inclui informações de download, instalação e uso. Após a instalação dos programas verificou-se que o hardware disponível comportava o funcionamento dos mesmos.

\subsection{Produção}

As vídeo-aulas foram gravadas no formato quadro fixo adjacente" (Crook \& Schofield, 2017) onde a imagem do narrador do vídeo aparece em um quadro fixo adjacente à apresentação de slides. A gravação foi feita aproveitando a iluminação natural do dia, evitando os horários entre 11:30h e 14:30h. Na ausência de iluminação profissional, usar a luz natural melhora a imagem do professor captada pela webcam do computador. O professor deve ficar de frente para a fonte de luz (janela) e a câmera do computador de frente para o professor e de costas para a fonte de luz.

O roteiro não pode ser lido, pois isso ficaria evidente na imagem da câmera. Muitas vezes foi necessário repetir a fala para evitar vícios de linguagem e gagueira provocados pelo desconforto de estar sendo gravado. A vídeo-aula gravada no Active Presenter ficou com 39:44 minutos e a gravada no OBS Studio ficou com tempo de 34:35 minutos. Esta diferença foi compensada na edição dos vídeos.

Os dois programas de gravação permitem que a tela do computador seja gravada. O Active Presenter permite que a apresentação seja construída ou carregada nele, porém nesse estudo, utilizamos o recurso de gravação de tela. Para gravar a tela pelo OBS Studio, é necessário deixar o arquivo do Power Point aberto no modo apresentação antes de iniciar a gravação. No Active Presenter, é possível iniciar a apresentação após iniciar a gravação da 
tela. Em ambos os programas, enquanto ocorre a gravação, o professor vê somente a apresentação do Power Point, não sendo possível se ver na câmera.

O Active Presenter é de mais fácil manipulação que o OBS Studio, pois para iniciar a gravação, basta clicar em -gavar vídeo". Ele abre um menu onde pode selecionar a webcam e o microfone, clicar em REC e ir para a tela da apresentação, pois a gravação já estará acontecendo. No OBS Studio é necessário criar cenas e adicionar as entradas em cada cena, como webcam, microfone, áudio do sistema, captura de tela, vídeo, etc. Se houver mais de uma cena, é necessário fazer a transição de uma cena para outra durante a gravação. Neste vídeo foram criadas a cena 1 com a imagem de abertura; a cena 2 com webcam e microfone para gravar a imagem e fala da professora e captura de tela para gravar apresentação de slides; e a cena 3 com o vídeo para encerrar a aula, webcam e microfone. Depois de adicionar as cenas é possível iniciar as gravações.

A aula gravada no OBS Studio apresentou problemas de áudio, onde a voz da professora sumia eventualmente. A gravação foi repetida trocando o microfone, alterando as configurações de áudio do programa, eliminando ontros softwares que poderiam estar trabalhando em segundo plano, re-instalando o OBS Studio, porém nada disso foi eficiente para eliminar o problema. Este vídeo sem edição pode ser visto no link (https://youtu.be/nJIq tNI3Ss) e o vídeo gravado no Active Presenter (https://youtu.be/U9rT3pnOpe8) foi selecionado para ser editado.

\subsection{Pós-Produção}

Os vídeos foram editados nos programas Active Presenter e Shotcut. O Active Presenter permite que o vídeo seja editado tão logo a gravação do mesmo seja encerrada. É mais intuitivo que o Shotcut, por apresentar de forma mais direta as possibilidades de edição. A Figura 2 apresenta a interface do programa Active Presenter em seu momento de edição.

O vídeo é gravado e separado por camadas que são apresentadas na linha do tempo. A primeira, denominada Slides, é a gravação da apresentação do Power Point; Audio_004 é o som captado pelo microfone; Webcam_001.2_1 é a gravação da imagem do professor e Vídeo_001_1 é o vídeo que foi incorporado ao final da aula, demonstrando o funcionamento e os equipamentos de limpeza e seleção de batatas. Depois do vídeo gravado foi adicionado um vídeo de abertura, e uma música de fundo que foram adicionadas ao sistema na camada denominada Objetos, já que a música inicia imediatamente após a abertura. 


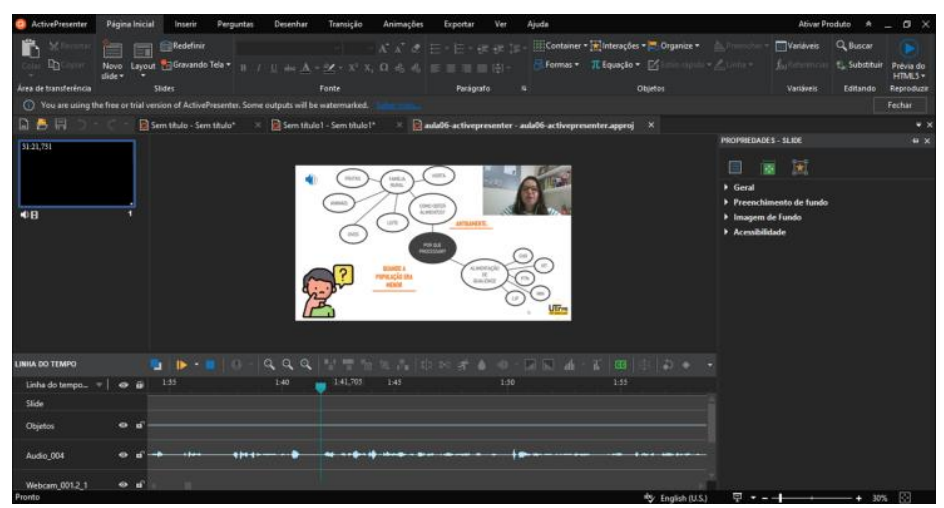

Fig. 2 Interface do programa Active Presenter

Fonte:o autor

A principal diferença no uso do Active Presenter e do Shotcut é a forma de adicionar as camadas para editar o vídeo. Como o vídeo a ser editado é produzido diretamente no Active Presenter, as camadas de áudio, câmera e slides já estão no programa separadas. Já no Shotcut, o vídeo a ser editado corresponde a uma única camada, mesmo tendo todas as informações do vídeo que será editado no Shotcut. Podemos ver a interface do programa Shotcut na Figura 3.

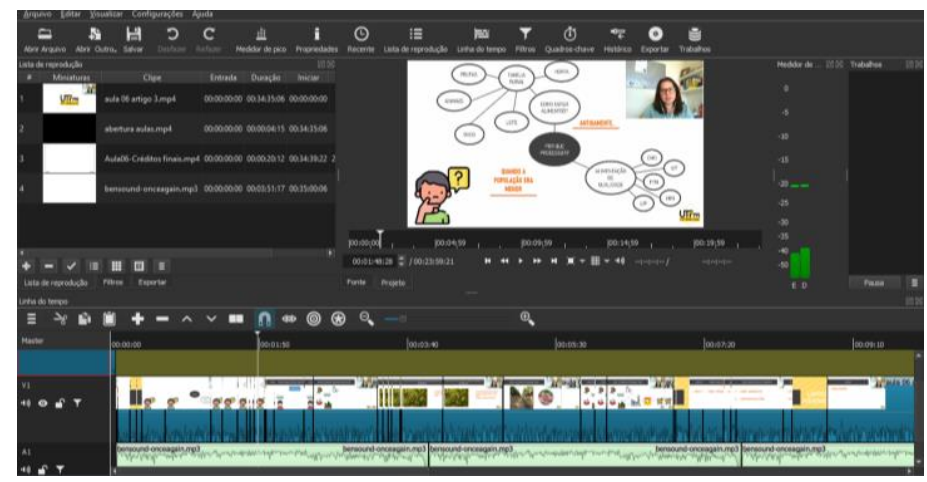

Fig. 3 Interface do programa de edição Shotcut

Fonte:o autor

A Figura 3 mostra que a edição do vídeo no Shotcut está em três camadas: em V1 está o vídeo de abertura, em V2 está a vídeo-aula gravada e o vídeo de encerramento e em A1 está a música de fundo. O programa permite a separação do áudio da vídeo-aula, mas é necessário fazer a solicitação. Da mesma forma que o Active Presenter, o Shotcut funciona com o empilhamaento dos elementos do vídeo em camadas, onde a camada superior se sobrepõe às camadas inferiores. A forma de adicionar os arquivos de vídeo e de aúdio na edição do Shotcut é menos intuitiva. Primeiro é preciso abrir o arquivo dentro do programa, 
depois adicionar ele na lista de reprodução, adicionar uma faixa de áudio ou de vídeo à linha do tempo e, por fim, adicionar o arquivo a ser editado na linha do tempo.

\section{Considerações Finais}

Embora seja mais simples operar o programa Active Presenter, depois que se compreende como adicionar os arquivos no programa, o Shotcut permite uma edição mais refinada, gerando um vídeo editado com melhor qualidade. Isso pode ser demonstrado na edição da vídeo-aula gravada no Active Presenter, com duração inicial de 39:44 minutos, que quando foi editada no Active Presenter ficou com duração total de 31:17 minutos (https://youtu.be/64kBnus12-I), enquanto que editada no Shotcut ficou com duração de 26:53 minutos (https://youtu.be/mdI2U6Wxkyg), mantendo as mesmas informações, somente retirando as partes com erros ou tempos de espera de fala. Conclui-se que a melhor experiência foi a gravação no Active Presenter e a edição no Shotcut, pois permitiu um processo de gravação mais simples e uma edição mais apurada já que foram retiradas as partes desnecessárias do vídeo, produzindo uma vídeo-aula com ajuste fino na edição.

\section{Agradecimentos}

Agradecemos o apoio do Instituto Politécnico de Bragança, em Portugal e da Universidade Tecnológica Federal do Paraná no Brasil.

\section{Referências}

Alexa. ([s.d.]). Competitive Analysis, Marketing Mix and Traffic-Youtube.com. Recuperado 25 de junho de 2020, de https://www.alexa.com/siteinfo/youtube.com

Bonini-Rocha, A. C., Oliveira, L. F. de, Rosat, R. M., \& Ribeiro, M. F. M. (2014). Satisfação, percepção de aprendizagem e desempenho em vídeo aula e aula expositiva. Ciências \& Cognição, 19(1), Article 1. http://www.cienciasecognicao.org/revista/index.php/cec/article/view/871

Chen, Y.-T. (2013). A Study of Learning Effects on E-Learning with Interactive Thematic Video: Journal of Educational Computing Research. https://doi.org/10.2190/EC.47.3.c

Crook, C., \& Schofield, L. (2017). The video lecture. The Internet and Higher Education, 34, 56-64. https://doi.org/10.1016/j.iheduc.2017.05.003

Flaticon. ([s.d.]). Flaticon, the largest database of free vector icons. Flaticon. Recuperado 26 de junho de 2020, de https://www.flaticon.com/

Spanhol, G. K., \& Spanhol, F. J. (2009). Processos de produção de vídeo-aula. Renote, 7(1), Article 1. https://doi.org/10.22456/1679-1916.13903 